\title{
Echolocation intensity and directionality of perching and flying fringe-lipped bats, Trachops cirrhosus (Phyllostomidae)
}

\author{
Annemarie Surlykke ${ }^{1 *}$, Lasse Jakobsen ${ }^{1}$, Elisabeth K. V. Kalko ${ }^{2}$ and Rachel A. Page ${ }^{3}$ \\ ${ }^{1}$ Institute of Biology, University of Southern Denmark, Odense M., Fyn, Denmark \\ 2 Institute of Experimental Ecology, University of UIm, UIm, Germany \\ ${ }^{3}$ Smithsonian Tropical Research Institute, Balboa, Ancón, Panamá
}

Edited by:

Mariana L. Melcón, Fundación

Cethus, Argentina

Reviewed by:

Gareth Jones, University of Bristol, UK

Peter Stilz, University of Tübingen, Germany

*Correspondence:

Annemarie Surlykke, Institute of Biology, University of Southern

Denmark, SDU, DK-5230,

Campusvej 55, Odense M., Fyn,

Denmark

e-mail:ams@biology.sdu.dk
The Neotropical frog-eating bat, Trachops cirrhosus, primarily hunts stationary prey, either by gleaning on the wing, or in a sit-and-wait mode hanging from a perch. It listens passively for prey-generated sounds, but uses echolocation in all stages of the hunt. Like other bats in the family Phyllostomidae, T. cirrhosus has a conspicuous nose leaf, hypothesized to direct and focus echolocation calls emitted from the nostrils. T. cirrhosus is highly flexible in its cognitive abilities and its use of sensory strategies for prey detection. Additionally, T. cirrhosus has been observed to echolocate both with closed and open mouth. We hypothesize that its flexibility extends to echolocation call design. We investigated the effect of hunting mode, perching or flying, as well as the effect of mouth opening, on the acoustic parameters and directionality of the echolocation call. We used a multi-microphone array, a high-speed video camera, and a microphone-diodevideo system to directly visualize the echolocation sound beam synchronized with the bat's behavior. We found that $T$. cirrhosus emits a highly directional sound beam with half amplitude angle (HAM) of $12-18^{\circ}$ and DI (directionality index) of $\sim 17 \mathrm{~dB}$, among the most directional bat sonar beams measured to date. The directionality was high both when flying and when perching. The emitted intensity was low, around $88 \mathrm{~dB} S P L$ at $10 \mathrm{~cm}$ from the mouth, when hanging, but higher, around $100 \mathrm{~dB} S P L$ at $10 \mathrm{~cm}$, when flying or just before take-off. Our data suggests that the limited search volume of T. cirrhosus sonar beam defined by the high directionality and the rather low intensity of its echolocation calls is adapted to the highly cluttered hunting habitat and to the perch hunting mode.

Keywords: echolocation, directionality, intensity, sonar beam, perch hunting

\section{INTRODUCTION}

Echolocation is one of the key adaptations enabling the successful and rapid radiation of bats. Bats emit high frequency signals and use the returning echoes to orientate in darkness, to detect and localize prey, and to find roosts. There is considerable variation in echolocation call design across bat species, and a large number of studies have shown that within species, individuals can flexibly adapt the time- and frequency features of their echolocation calls to the situation and task at hand (e.g., Neuweiler, 1989; Schnitzler and Kalko, 2001). Recent data demonstrate that this flexibility also extends to the intensity (Brinkløv et al., 2010) and directionality of the sonar signal (Surlykke et al., 2009b; Jakobsen et al., 2013). Intensity and directionality are critical in defining the sonar search volume, i.e., the volume of space ahead of the bat in which objects are ensonified with sufficient sound energy to reflect detectable echoes. Some bats hunt in a sitand-wait hunting mode, hanging from a perch and scanning the surroundings for potential prey by rotating the head and body. Perch hunting is often seen in rhinolophid bats (Neuweiler et al., 1987; Jones and Rayner, 1989), but also in other families, e.g., Phyllostomidae (Weinbeer and Kalko, 2004), Megadermatidae
(Audet et al., 1991), and Nycteridae (Fenton et al., 1987). Because echolocation call production can be coupled with wing beats, it may require close to no extra energy to produce echolocation sounds in flight (Speakman and Racey, 1991). However, overall flight costs are high and perch hunting is far less costly energetically than continuous flight (Voigt et al., 2010). It is, however, unknown whether perch hunting poses special constraints on the echolocation, thus, promoting adaptive changes to intensity and directionality as well as other acoustic features of the echolocation calls.

The fringe-lipped bat, Trachops cirrhosus (Phyllostomidae), occurs in the Neotropics, from southern Mexico to southern Brazil (Reid, 1997). It roosts in hollow trees and flies a short distance $(1-2 \mathrm{~km})$ to its foraging grounds, where it gleans prey over a relatively small area (3-4 ha) (Kalko et al., 1999). T. cirrhosus uses both continuous flight and perch hunting when foraging. Radio-telemetry studies found that $T$. cirrhosus makes long flights ( $>2$ min) early in the evening, hunting on the wing along streams and over ponds, likely predominantly for frogs, i.e., túngara frog [Engystomops (formerly Physalaemus) pustulosus]. Later in the night, when frog calling activity decreases, T. cirrhosus switches to 
perch hunting, sallying from a perch in short flights of less than $1 \mathrm{~min}$, presumably hunting insect prey, such as forest katydids (Kalko et al., 1999). T. cirrhosus relies primarily on prey-emitted acoustic cues to detect and localize its prey, and can use speciesspecific frog mating calls to assess prey palatability (Tuttle and Ryan, 1981). It has been suggested that T. cirrhosus can detect the loud, conspicuous calls of túngara frogs and other preferred frog species even while on the wing, but when listening for katydid wing beat or landing sounds, or eavesdropping on their faint, high frequency and often low duty cycle calling song, a hang-and-wait strategy is more effective (Kalko et al., 1999).

Eavesdropping on prey-generated acoustic cues has been well documented in T. cirrhosus, both in field and flight cage experiments (Ryan et al., 1982). However, even though T. cirrhosus primarily uses passive listening to detect and localize its prey, it produces echolocation calls throughout the hunting approach (Barclay et al., 1981). Flight cage experiments show that it can use echolocation and spatial memory (Page and Ryan, 2008) to detect prey that falls silent upon approach, and can use both echolocation and chemical cues in the final stages of prey assessment (Page et al., 2012). T. cirrhosus emits typical phyllostomid calls, consisting of short, multiharmonic sweeps of low intensity. In confined space, such as the laboratory, most energy is in the third (sweeping from $110 \mathrm{kHz}$ down to $80 \mathrm{kHz}$ ) and fourth harmonic and call duration is less than $1 \mathrm{~ms}$. The cruising pulse rate is around $25 \mathrm{~Hz}$, but in the final phase before attacking their prey the rate increases to around $80 \mathrm{~Hz}$ (Barclay et al., 1981).

A member of the phyllostomid family of leaf-nosed bats, T. cirrhosus has a prominent nose leaf, extending from the base of the nostrils. Nose leaves of phyllostomids are fairly similar in overall shape but differ greatly in size (Vanderelst et al., 2010). It is generally accepted that phyllostomids emit echolocation calls through the nostrils. In all probability, the nose leaf, which is not found in mouth-emitting bat families like e.g., Vespertilionidae or Emballonuridae, has a role in shaping and steering the sonar sound beam (Hartley and Suthers, 1987; Vanderelst et al., 2010). However, directionality has rarely been measured directly, and new data from flying Carollia perspicilliata (Brinkløv et al., 2011) demonstrated a narrower sonar beam when flying than earlier data from sitting bats had indicated (Hartley and Suthers, 1987). Thus, phyllostomid bats, like vespertilionids, may have the ability to flexibly modify their beam shapes to adapt to a given situation (Surlykke et al., 2009b; Jakobsen and Surlykke, 2010; Jakobsen et al., 2013). Since Trachops hunts while hanging from a perch as well as on the wing, it offers an excellent opportunity to study whether sonar search volume (intensity and directionality) is adapted to hunting strategy. In addition to listening for the sounds of its prey, we also frequently observed that $T$. cirrhosus opened its mouth while echolocating from a perch. Several other phyllostomid species have also been observed to open the mouth while echolocating (Tschapka, page 11 in LaVal and Rodrìguez-H, 2002), which might influence the sound emission by changing the emission site or altering the headrelated transfer function. Thus, a second purpose of this study was to determine if $T$. cirrhosus adds an extra level to its sonar flexibility by being able to echolocate both through the nostrils and through the open mouth.

\section{MATERIALS AND METHODS \\ ANIMALS}

We captured bats on Barro Colorado Island, in Soberanía National Park and the areas surrounding Gamboa, Panama, using mist nets set along small streams and ponds at dusk. We recorded echolocation calls from $6 \mathrm{~T}$. cirrhosus with a mean capture weight of $32.5 \mathrm{~g}$ (range 28-37 g) and mean forearm length of $58.8 \mathrm{~mm}$ (range 57.2-60.7 $\mathrm{mm}$ ). We measured the length of the lancet of the nose leaf for 9 other individuals (Figure 1) from the tip of the nose leaf to the center of a line connecting the two nostril centers (mean \pm SEM: $9.2 \pm 0.3 \mathrm{~mm}$ ), as measured in Brinkløv et al. (2011). In 2006, we recorded from two females, in 2008, from two males, and in 2012, from two males. All bats were held and tested in screened, outdoor flight cages. Bats from 2006 and 2008 were tested in a $4.5 \times 4 \times 2.5 \mathrm{~m}$ flight cage on Barro Colorado Island; bats from 2012 were tested in a $5 \times 5 \times 2.5 \mathrm{~m}$ flight cage in Gamboa. We recorded the bats in two behavioral situations: (1) while they were hanging from their perch, a short branch in the upper corner of the flight cage ca. $1.75 \mathrm{~m}$ above the floor, scanning the environment by turning head and body, and (2) while they were flying toward a loudspeaker placed on the floor of the flight cage ca. $2.5 \mathrm{~m}$ horizontal distance from the perch (Figure 2).

\section{SOUND RECORDINGS}

We recorded all bats with arrays of $1 / 4^{\prime \prime}$ (G.R.A.S) microphones (without grids) amplified by G.R.A.S. 12AA or Avisoft $1 / 4^{\prime \prime}$ power modules. We digitized the signals at 250,500 , or $300 \mathrm{kHz}$ per channel using either an IOTech Wavebook or an Avisoft USGH (Avisoft Bioacoustics, Berlin, Germany), and stored data on a laptop computer. In 2006, we used four microphones in a T-shaped array with approximately $30 \mathrm{~cm}$ distance between microphones placed above the loudspeaker on the floor. In 2008, we used 10 microphones with ca. $30 \mathrm{~cm}$ distance, 8 G.R.A.S. $1 / 4^{\prime \prime}$ on a linear

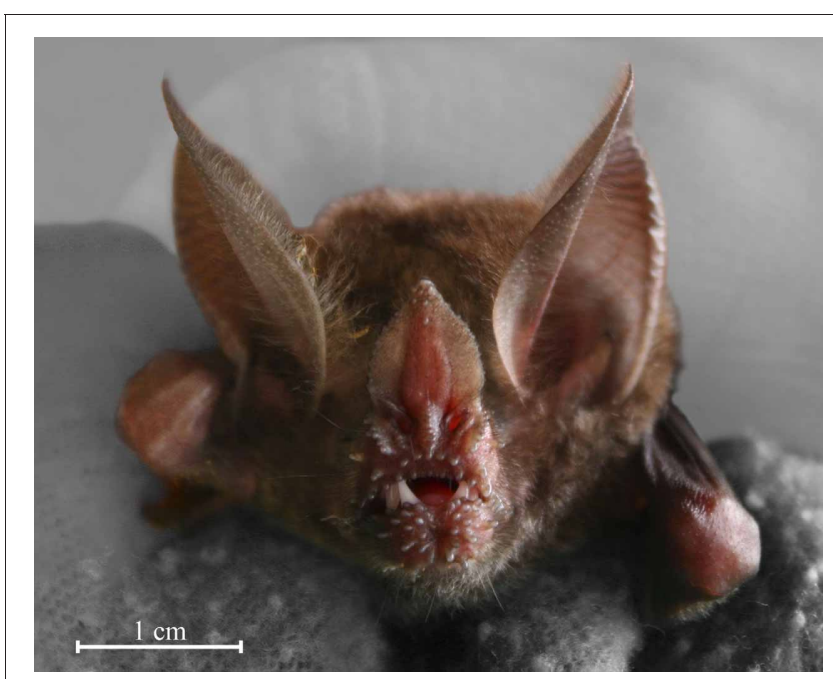

FIGURE 1 | Trachops cirrhosus has a nose leaf with a lancet that is $\mathbf{9} \mathbf{~ m m}$ from tip to nostrils. The large ears and the characteristic tubercles around the chin and lips are also clearly visible. 
A
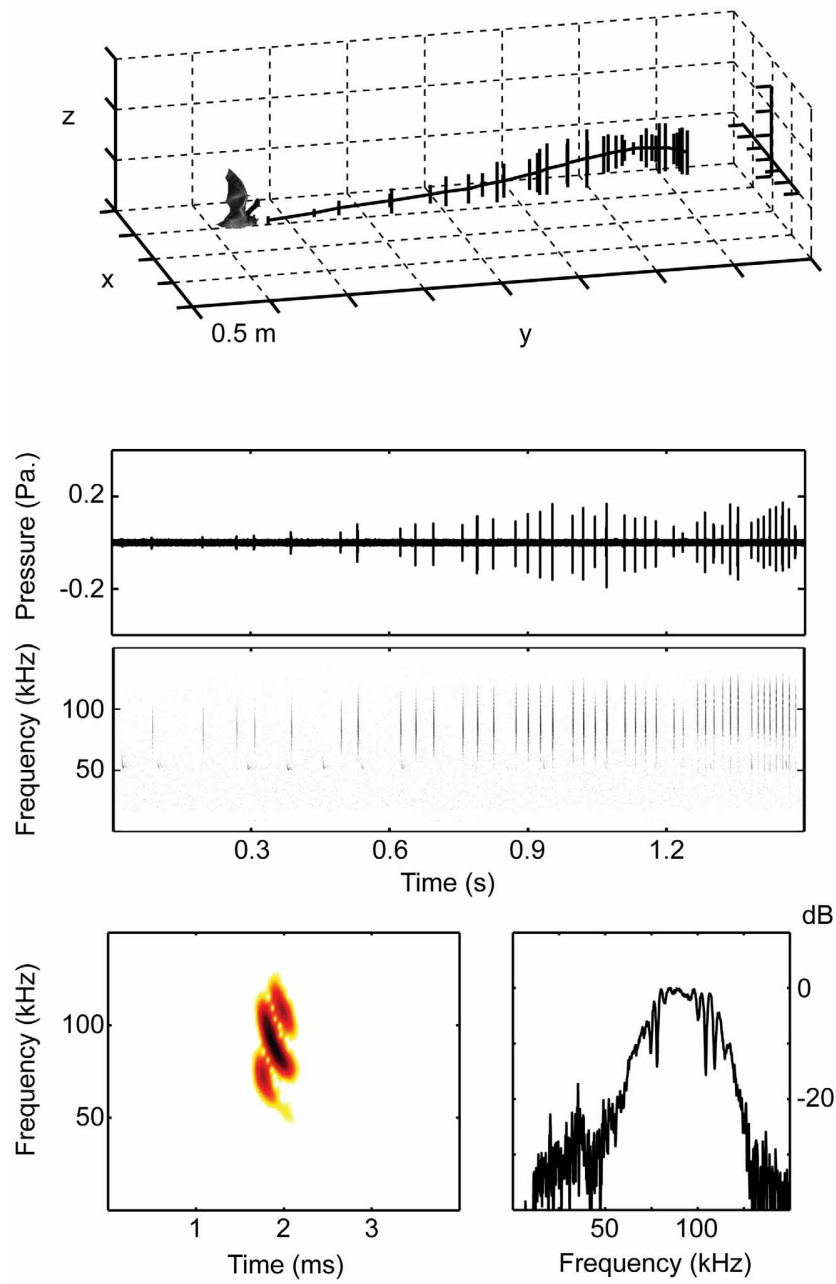

FIGURE 2 | The bats were recorded with microphone arrays when hanging from a perch or when flying. (A) Shows the set-up in 2012 with 11 microphones in a cross-shaped array, 7 horizontal and 3 above and 1 below the center microphone. The middle panel shows oscillograms and spectrograms of the echolocation calls emitted in the flight illustrated in the upper panel, where each vertical line is a call. The lower panel shows a spectrogram and a spectrum of one of the calls from the same sequence.

(B) Shows a recording from 2008 of a perching bat. The 10 microphone array
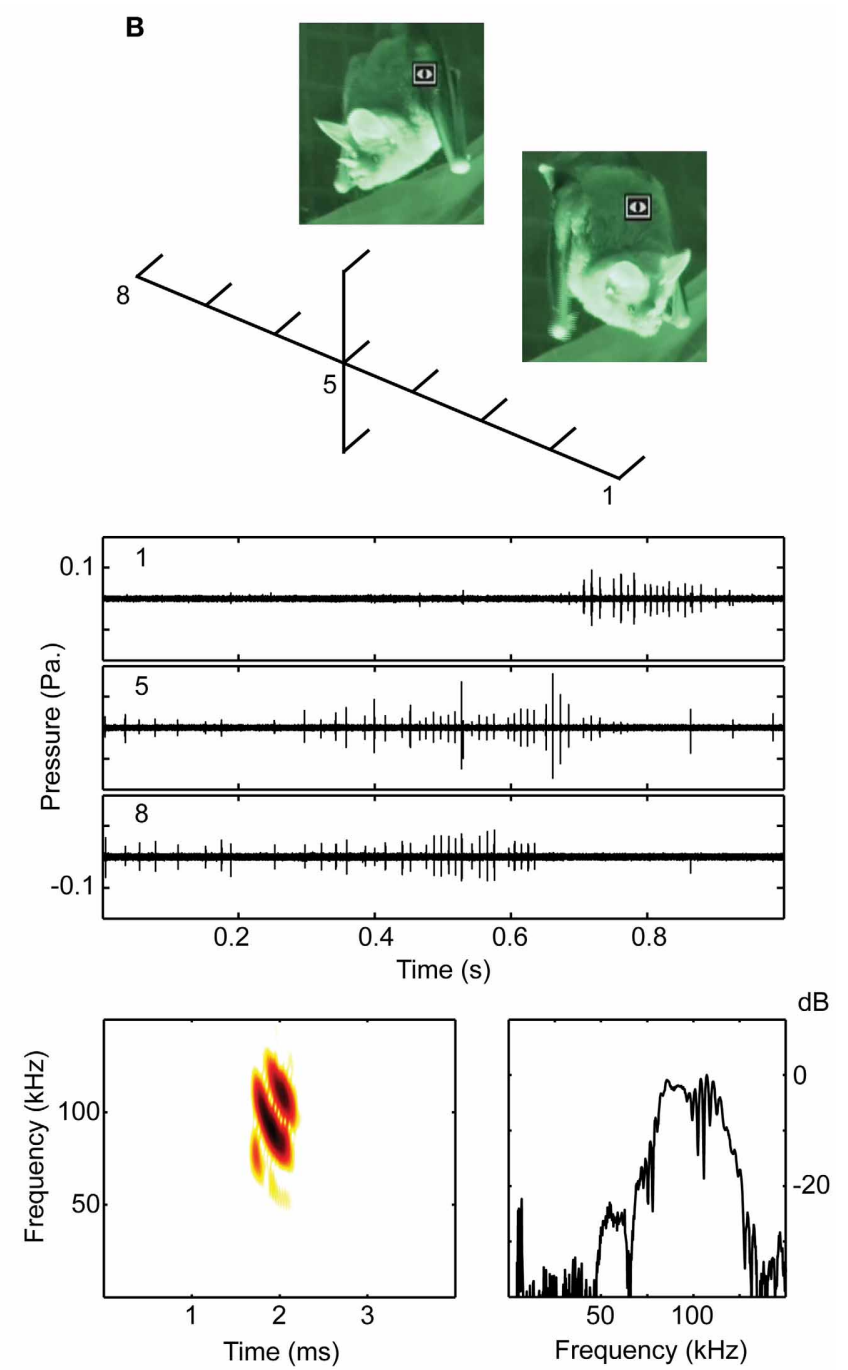

had 8 microphones on a horizontal line at the height of the bat's mouth. The middle panel shows oscillograms of a single echolocation sequence, recorded simultaneously on microphones 1, 5 and 8 . Stills from the infrared video illustrate the bat turning its head from right to left. Due to the high directionality of the sonar beam, the calls are only visible on the channels at which the bat is aiming, i.e., channel 8 when the bat is facing right in the beginning and channel 1 when the bat is facing left in the end of the trial. Below are shown spectrum and spectrogram of one of the calls from this sequence. horizontal line and an Avisoft condenser microphone (CM16) above and below the 5 th microphone, which was $90 \mathrm{~cm}$ in front of the bat and at the same height as its mouth. In 2012, we used 11 1/4" G.R.A.S. microphones with $25 \mathrm{~cm}$ distance in a cross shaped array, 7 horizontally and 3 above and one below the center (4th) microphone. The array was ca. $5 \mathrm{~m}$ from the wall on which the bats perched (Figure 2).

\section{VIDEO RECORDINGS}

All trials were conducted in red (25W red light bulb) and infrared light (Wisecomm IR045 LED and Conrad infrared spot) to minimize the bat's use of vision. All trials were video-recorded.
In 2006, we used a Sony nightshot DCR-SR45 camcorder. Bats were presented with speakers broadcasting the calls of túngara frogs, a preferred prey species, and rewarded with a prey item on the speaker. In 2008, we recorded bats hanging from a perch with two Sony nightshot DCR-SR45 camcorders. One video focused on the bat's head and the other on an array of diodes connected directly via custom build amplifiers to a second $4 \times 4$ array of microphones (Knowles) spaced by $46 \mathrm{~cm}$ horizontally and $26 \mathrm{~cm}$ vertically. The minimum distance to the bat was $1 \mathrm{~m}$ translating into a resolution of around $20-30^{\circ}$. The diodes had 16 steps of light from green over yellow to red over a $30 \mathrm{~dB}$ range, and were adjusted to just emit green 
light at background noise. Thus, the diodes corresponding to the microphone(s) ensonified by the bat would emit orange or red light according to the sound level on the microphone. We combined the footage from the two camcorders into one movie using an Extron PIP 422 Picture-in-Picture Processor thus giving us on-line synchronized feedback simultaneously about the bat's head and nose leaf position, mouth opening, and sonar beam aim. In 2008, we additionally recorded the perching bats with high-speed video (CamRecord 600, Optronis, Germany) at 500 frames per second. The high-speed video was synchronized to an Avisoft Ultrasound recording system using an Avisoft condenser microphone (CM16, Avisoft Bioacoustics, Berlin, Germany) and a one-channel Avisoft USG digitizer. The high speed video and synchronized sound was stored on a laptop computer. Both video systems were used to find sequences where the mouth was clearly open, and the diodes were used to control that the sonar beam hit the diodes in the directions the head and nose leaf was aiming.

In 2012, we recorded sounds from two bats, both when they were perching and when they were flying toward a speaker broadcasting frog calls for a food reward. In contrast to the previous recordings, the bats would perch at a relatively random location on the cage wall and thus approach the speaker from a variation of directions. The bats were video recorded with a Sony HDRCX550V camcorder, which was adjusted to the bat's position before each trial.

\section{ANALYSES}

We estimated source levels and directionality in flight for the two bats recorded in 2006 and the two bats recorded in 2012 . We obtained the bats' flight paths using the arrival time differences at the microphones to localize the bats at the time of each echolocation emission. We determined source levels and directionality only from calls where the beam aim was in the center of the microphone array. Because of the array configuration we obtained only horizontal directionality from the bats recorded in 2006 and 2008, but both directions for the 2012 data. Using the estimated positions, we calculated source levels (emitted intensity referenced to $10 \mathrm{~cm}$ from the bat's mouth measured in $\mathrm{dB}$ SPL rms) by adding transmission loss (geometric spreading loss and atmospheric attenuation) and microphone directionality (Brüel and Kjær, 1982) using the method described in Jakobsen et al. (2012).

We estimated source levels and directionality for perching bats with either open or closed mouth for the two bats recorded in 2008 and for the two bats recorded in 2012. In 2008, the array allowed for determinations of the horizontal directionality, but only indications of beam aim in the vertical plane. We used the camcorder video combined with the diode display to guide us to sequences, where the bat's mouth was either clearly open, or clearly closed, and analysed the acoustic behavior in detail by using the high speed video and $1 / 4^{\prime \prime}$ microphone recordings.

Directionality can be quantified as half amplitude angle (HAM) or directivity index (DI). HAM is the off-axis angle, where the amplitude of the signal has declined by $6 \mathrm{~dB}$. DI compares on-axis sound pressure with the sound pressure of an omnidirectional emitter producing a signal of equal energy. For all estimates of source level and directionality, we estimated beam-aim by fitting a 2 nd order polynomial to the recorded beam pattern, using the peak of the polynomial as a proxy for beam aim. For details see Brinkløv et al. (2011). We calculated the DI as in Møhl et al. (2003):

$$
D I=\log _{10}\left(\frac{2}{\sum_{i=1}^{N}\left(b_{i} \times \sin \left(\nu_{i}\right) \times \Delta \nu\right)}\right)
$$

where $b_{i}$ is the $i$ th sample of an interpolation of the measured beam pattern, $v_{i}$ is the angle, between 0 and $\pi$ radians, and $\Delta v$ is the angular interval between interpolation points. $N$ is the number of samples. The expression assumes rotational symmetry. To obtain the interpolation of the measured beam pattern, we pooled the measured relative sound pressures (both horizontal and vertical) into $1^{\circ}$ bins and averaged them. We then extrapolated the measurements to obtain the complete sound field around the bat by fitting a second order polynomial to the average of the measured beams (Figures 3, 4).

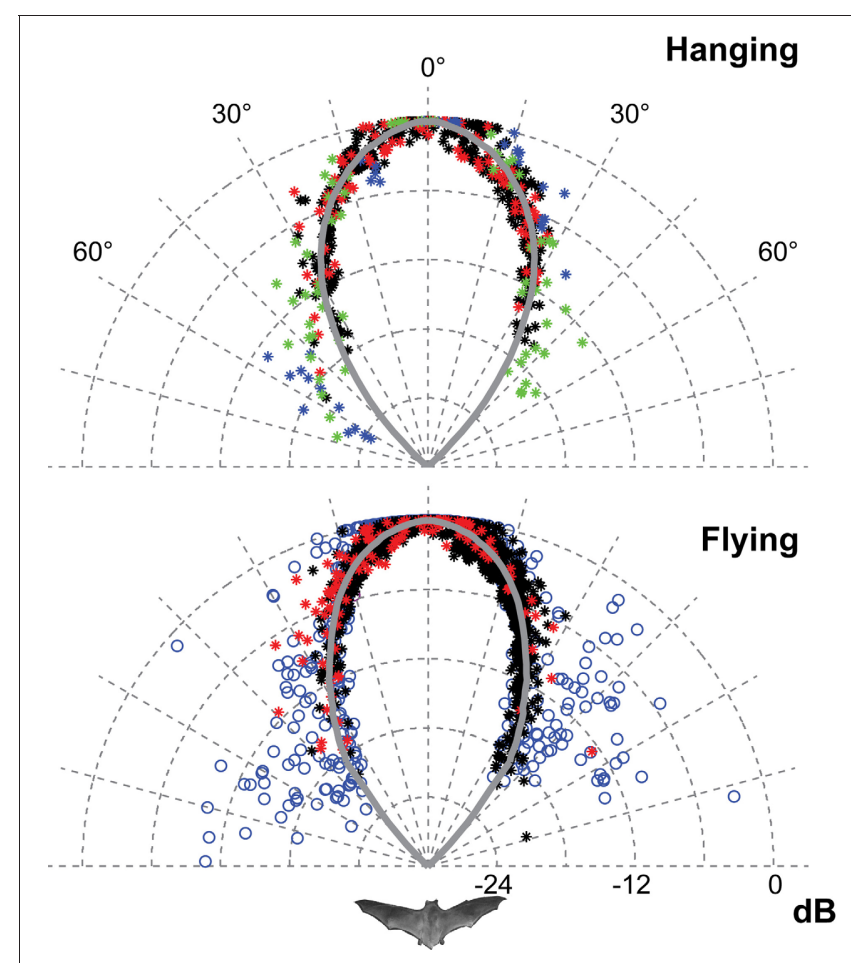

FIGURE 3 | The horizontal directionality when flying and hanging. The data for hanging bats are from 2012 (red and black) and from 2008 (blue and green). The data for flying bats are from 2012 (red and black) and from 2006 (blue). Each point is the normalised amplitude in that direction. The curves are the average of the measured values pooled in $1^{\circ}$ bins and extrapolated using a fitted second order polynomial. Only data from 2012 was used for the traces and DI estimates because of the higher degree of control of beam aim. The sonar beam is very directional, both when flying and hanging. HAM was $18^{\circ}$. 


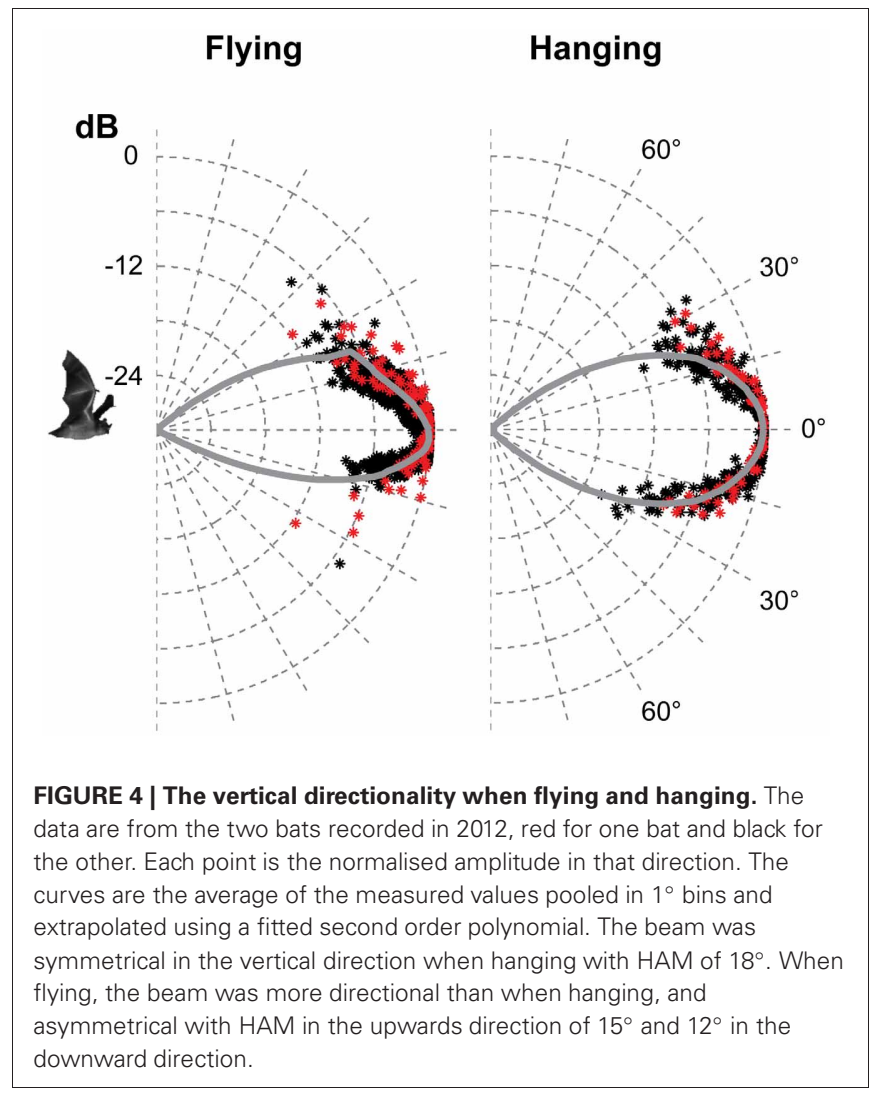

\section{RESULTS \\ ECHOLOCATION SOUNDS WHEN FLYING AND HANGING FROM A PERCH}

When leaving the perch and flying toward the loudspeaker the bats always echolocated and we never observed opening of the mouth. The echolocation calls had main energy in the third harmonic with $F_{\text {peak }}$ (the frequency with maximum energy) at ca. $90 \mathrm{kHz}$, and less energy in the second and fourth harmonic ( $F_{\text {peak }}$ at 60 and $120 \mathrm{kHz}$, respectively). The calls were short, between 0.3 and $0.9 \mathrm{~ms}$, and repeated with irregular pulse intervals of 30-120 ms when the bat was far away from the loudspeaker. At closer range the sonar pulses were grouped with increasing pulse number and decreasing pulse interval within the groups, which were $70-100 \mathrm{~ms}$ long, consisting of 3-10 pulses. Within groups the pulse interval was relatively constant (Figure 2A).

Since the source level decreased as the bat approached the loudspeaker and simultaneously got closer to the floor, we calculated source levels from calls emitted, when the bats were still far enough from the microphone array. At this distance we also got good $\mathrm{S} / \mathrm{N}$ on all four or all eleven microphones. The maximum source levels (referenced to $10 \mathrm{~cm}$ ) were recorded immediately after the bat left the perch and were $103 \pm 3 \mathrm{~dB}$, and $99 \pm 4 \mathrm{~dB}$ for the two bats in 2006 and $102 \pm 3 \mathrm{~dB}$ and $99 \pm 3 \mathrm{~dB}$ for the two bats in 2012 .

When on the perch, the bats often hung silently for long periods, but they echolocated when they lifted their heads and started scanning the surroundings, turning the head and the whole body while rapidly moving the pinnae of the ears back and forth. A typical emission pattern is illustrated in Figure 2B. Bats emitted trains of pulses with pulse intervals ranging from 20 to $120 \mathrm{~ms}$, often $30-50 \mathrm{~ms}$. The pulse duration was the same as when flying, i.e., around $0.5-0.8 \mathrm{~ms}$ and again the main energy was in the third harmonic with $F_{\text {peak }}$ at $85-90 \mathrm{kHz}$. The apparent amplitude modulations (Figure 2B, middle panel) are not due to changes in emitted sound level, but reflect the bats' rapid scanning movements combined with the directionality of the calls. From the video we determined approximate scanning angles. The body turned ca. $45^{\circ}$ from extreme to extreme, in addition the head turned an extra ca. $45^{\circ}$, thus totaling ca. $90^{\circ}$ turn of head aim angle. While perching the source level was $86 \mathrm{~dB} \pm 10 \mathrm{~dB}$ SPL and $88 \mathrm{~dB} \pm 7 \mathrm{~dB}$ SPL for the two bats recorded in 2008. Right before taking off from the perch they emitted more intense calls, with source levels ca. $10 \mathrm{~dB}$ louder: $99.7 \pm 3.4 \mathrm{~dB}$ for the two 2008 bats, demonstrating that they control the emitted amplitude over a large dynamic range. In 2012, the source levels when the bats were perching were estimated to be higher, $102 \pm 2 \mathrm{~dB}$ and $98 \pm$ $4 \mathrm{~dB}$ SPL. The difference is likely to be caused by the much longer distance from the hanging bat to the microphone array in 2012 (Figure 2), only allowing for recording of the loudest calls directed toward the array.

\section{DIRECTIONALITY OF THE ECHOLOCATION SOUNDS}

We determined the directionality in three different situations: (i) flying, (ii) hanging from the perch with closed mouth, and (iii) hanging with open mouth. We never observed any of the six bats flying with open mouth, but video from 2008 showed several sequences where the bats had open mouth while echolocating from the perch (Figure 2B).

Only the horizontal directionality could be extracted from the 2006 and 2008 data, but both vertical and horizontal directionality were determined from the 2012 data (Figures 3 and $\mathbf{4}$ red and black data points). Estimates of beam shapes and statistical analyses were performed on the 2012 data, where we recorded with many microphones, but the values for 2008 confirm the measurements and are plotted in the same graphs (Figure 3 blue and green data points). The beam was narrow with a horizontal HAM of $18^{\circ}$, both when flying and hanging (Figure 3). In the vertical direction the measured directionality of the sonar beam was slightly narrower when the bats were flying than when hanging. HAM was ca. $18^{\circ}$ both up and down when hanging, but when flying HAM in the upward direction was $15^{\circ}$, and only $12^{\circ}$ in the downward direction (Figure 4). DI for the combined data-set, was $16 \mathrm{~dB}$ when hanging and $17 \mathrm{~dB}$ when flying. When all data from both scenarios were pooled, DI was $17 \mathrm{~dB}$. DI estimated using only the vertical directionality data was $17 \mathrm{~dB}$ for hanging bats and slightly more directional, $19 \mathrm{~dB}$, for flying bats. Hence, the data indicated a narrower and more asymmetrical beam when the bats were in flight (Figure 4) although the differences between directionality from hanging and flying bats were not statistical significant.We regressed angle (absolute value) against sound pressure $(\mathrm{Pa})$ for each bat's echolocation calls produced while flying and while hanging and found no difference in the slope of these two lines for either bat (two- and one-tailed tests 
for difference between two population regression coefficients, $P>0.05$ for all).

The data from bats hanging and echolocating with open mouth is somewhat inconsistent. One of the two bats recorded in 2008 emitted calls with open mouth that were indistinguishable from the calls emitted with closed mouth, for all acoustic parameters measured: spectrum, amplitude, and directionality. In contrast, when the other 2008 bat emitted calls with open mouth, there was an additional pronounced peak in the spectrum around the first harmonic (the fundamental) at $30 \mathrm{kHz}$, which was not seen when this bat echolocated with the mouth closed. The directionality at $30 \mathrm{kHz}$ was as expected much broader than at $90 \mathrm{kHz}$ with HAM of $45^{\circ}$ (Figure 5). We did not have synchronized video documentation in 2012 to allow us to know exactly when the bats had open mouth, but we did not record any signals with a prominent fundamental from either of the two, neither when hanging nor when flying.

\section{DISCUSSION}

The recordings from all six T. cirrhosus showed typical phyllostomid echolocation calls, i.e., short, multiharmonic calls with most energy at high frequencies, around $90 \mathrm{kHz}$, in the third harmonic, and often of relatively low output intensity. Barclay et al. (1981) reported a peak frequency closer to $75 \mathrm{kHz}$. However, distance, off-axis recordings, as well as microphone directionality will all low-pass filter the sounds. Here we report spectral characteristics of calls recorded on-axis and compensated for those low-pass effects, implying that the emitted $F_{\text {peak }}$ is really around $90 \mathrm{kHz}$. The calls are very directional both while flying $(\mathrm{DI}=17 \mathrm{~dB})$ and while perching $(\mathrm{DI}=16 \mathrm{~dB})$.

The narrow sonar beam of $T$. cirrhosus corroborates data from Carollia perspicillata, (HAM $16^{\circ}$ horizontally and $14^{\circ}$ vertically and $\mathrm{DI}=17 \mathrm{~dB}$, calculated from the original data) the only other phyllostomid species for which directionality has been measured in freely flying bats (Brinkløv et al., 2011). C. perspicillata is somewhat smaller than $T$. cirrhosus (41-45 mm vs. 57-65 mm forearm length and $\sim 18 \mathrm{~g}$ vs. $\sim 30 \mathrm{~g}$ ) but the lancet of the nose leaf is almost the same size ( $8 \mathrm{~mm}$ vs. $9 \mathrm{~mm}$ ) (Brinkløv et al., 2011). Both bat species emit very similar echolocation signals, with $F_{\text {peak }}$ around $90 \mathrm{kHz}$. Measurements from anesthetized C. perspicillata (Hartley and Suthers, 1987) as well as modeled directionality from Phyllostomus discolor (Vanderelst et al., 2010) demonstrate that the high directionality in the vertical plane is due to the extended nose leaf whereas the two nostrils determine directionality in the horizontal plane. Presumably this holds for T. cirrhosus too, since the overall shape and size of the nose leaf are quite similar in all three species. Given the similarity in nose leaf morphology and echolocation call features it is not surprising that the sonar beam directionality is similar in C. perspicillata and T. cirrhosus. Still, it is important to note that the nose leaf is not the sound emitter, but instead likely functions as a baffle, and thus its exact size is not expected to affect the sound field as much and as predictably as the size of the emitter. In mouthemitting bats the emitter size appears to be the gape size and thus mouth-emitting bats presumably have more mechanical control over directionality (Jakobsen et al., 2013) than nostril-emitting bats. However, we are still far from understanding the functional

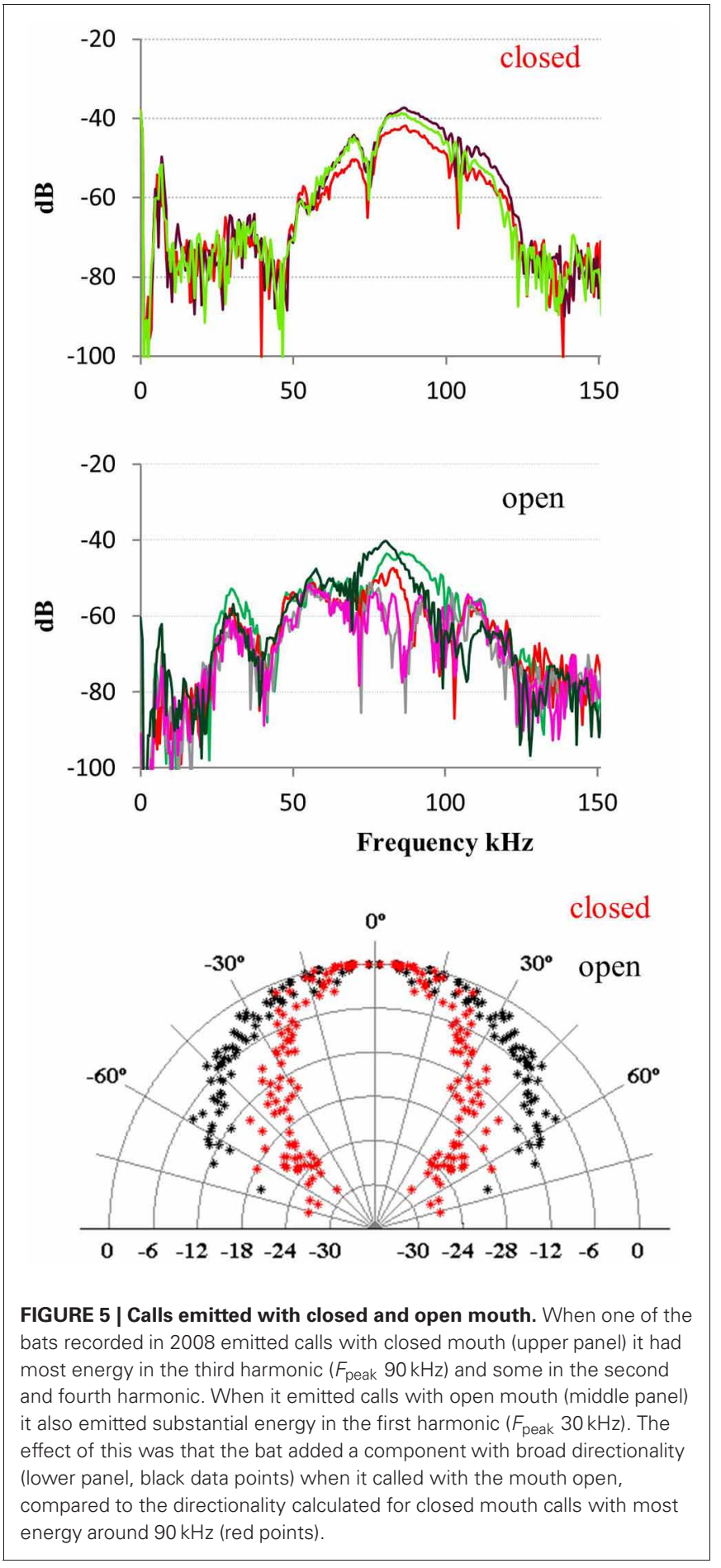

significance of motor control of nose leaf shape for sonar directionality (Hartley and Suthers, 1987; Feng et al., 2012). Vanderelst et al. (2010)'s model predicted a sonar beam that was symmetrical in the horizontal direction, but asymmetrical in the vertical direction, with a main lobe, which was wider above than below the acoustic axis. This is in accordance with our results for flying $T$. cirrhosus, whereas we found the vertical directionality to be symmetrical for hanging bats. The difference in sonar beam shape 
between hanging and flying bats was not statistically significant, probably due to the limited number of bats and data. Potentially, it indicates active control of the beam by bending the nose leaf in the vertical direction as has also been suggested for another phyllostomid bat, Macrophyllum macrophyllum (Weinbeer and Kalko, 2007), but further investigations are needed to clarify. If motor control of the nose leaf functions in dynamic active adaptation of the sonar beam axis and directionality in phyllostomid bat, in particular in flight, this once more emphasizes the importance of verifying models and measurements based on static morphological data with measurements from live naturally behaving bats.

Our data does not provide a clear conclusion to whether mouth opening is part of beam control. The data on one bat very clearly showed addition of lower frequency and thus a broader component of the beam, but data from only one bat is far from conclusive. If more data should show this to be of functional significance, it would add yet another level of flexible control of sonar search volume in $T$. cirrhosus or perhaps more generally in phyllostomids that open the mouth while echolocating.

While our data was not sufficient to show a significant difference between flying and hanging, it did show unequivocally that the beam is very narrow under all circumstances, similar to the beam of flying Carollia perspicillata. Although T. cirrhosus is carnivorous and C. perspicillata is frugivorous, they both take predominantly stationary prey in dense clutter, so in some respects their foraging ecology and demands on their echolocation systems are quite similar. An advantage of a very narrow beam is that it provides inherent directional information: if the energy is focused in a narrow angle around the axis of the sound beam, off axis objects will only be ensonified with low intensity sound and their echoes will be much reduced, leaving salient echo information to come from the direction of the sonar beam axis. Narrow beams thus also reduce the load on the processing system. Interestingly, the opposite adaptation is seen in vespertilionid bats, which broaden the beam in confined space (Surlykke et al., 2009b; Jakobsen et al., 2013). This difference might reflect that we have not yet understood the function of directionality. However, it might also be evidence of the enormous diversity of echolocating bats. Bats of different families have different strategies for detecting insects close to background vegetation: bats that use frequency modulated echolocation calls (FM bats) shorten the calls in closed habitats to make discrimination easier along the time axis, whereas bats that produce constant frequency calls (CF bats) produce extremely long narrow banded calls to discriminate between prey and background along the frequency axis (Schnitzler, 1967; Neuweiler, 1989; Moss et al., 2011). Along the same lines, we hypothesize that bats, depending on their phylogeny, hunting habitat, and prey type, use different strategies to deal with clutter. Phyllostomid bats hunting stationary prey may benefit from a narrow beam to decrease the load on the processing system and focus on the important target, whereas vespertilionid bats hunting primarily moving prey may broaden the beam to prevent the prey from escaping out of the echolocation beam (Goerlitz et al., 2010; Jakobsen and Surlykke, 2010) and also to "keep an eye" on the clutter in order not to collide while pursuing erratic prey.
Radio-tracking studies suggest that $T$. cirrhosus often switches from gleaning to perch-hunting (Kalko et al., 1999). Perch hunting is thought to reduce the energy consumption compared to constant flight (Neuweiler et al., 1987; Voigt et al., 2010). Another advantage of perch hunting is the possibility of using a wider search angle when hunting prey. Our data indicates a wide search angle $\left(\mathrm{ca} .90^{\circ}\right)$ for $T$. cirrhosus although not quite as wide as the $200^{\circ}$ estimated for rhinolophid bats (Neuweiler et al., 1987). In addition, scanning may reduce clutter. Bats sample their environment sequentially (Surlykke et al., 2009a), and when scanning perch hunting bats sequentially ensonify objects within a wide angle of directions. By integrating the input over time, they can create an auditory scene in great detail with much less off-axis clutter than a broader beam covering the same total angle would provide.

Finally, an underappreciated advantage of perch hunting might be an improved signal-to-noise ratio, since there is no wind noise from flight. Wind noise has never been measured for flying bats, but has been estimated to increase detection thresholds from the standard mammalian threshold of $0 \mathrm{~dB}$ SPL to around 20 dB SPL (Surlykke and Kalko, 2008). Stationary bats with large ears have been shown to have minimum hearing thresholds below $0 \mathrm{~dB}$ SPL (down to $-20 \mathrm{~dB}$ SPL) (Long, 1977; Hoffmann et al., 2008). When stationary, big ears not only function as large acoustic antennae, but by their independent movements, also provide directional information by differentiating and focusing incoming acoustic input. In flight, in contrast, big ears are likely to create even more noise due to their higher air resistance. If we assume a source level according to our data of around $100 \mathrm{~dB}$ $\mathrm{SPL}$ at $10 \mathrm{~cm}(\mathrm{rms})$ and an increase in detection threshold from 0 to $20 \mathrm{~dB}$ SPL when flying compared to hanging (conservative estimate given the large ears of T. cirrhosus, Figure 1), we can estimate detection ranges for insect-sized prey with a target strength of $-20 \mathrm{~dB}$ (Surlykke et al., 1999) using the simple form of the sonar equation:

$$
\mathrm{EL}=\mathrm{SL}-2 \mathrm{TL}+\mathrm{TS}
$$

$\mathrm{EL}=$ echo threshold level, $\mathrm{TL}=$ one way transmission loss (geometric spreading and atmospheric attenuation at $90 \mathrm{kHz}, 28^{\circ} \mathrm{C}$, $80 \%$ relative humidity), TS $=$ target strength (Surlykke and Kalko, 2008). A perching bat would be able to detect insect echoes at a distance of $2.9 \mathrm{~m}$, but only at $1.6 \mathrm{~m}$ when flying. The bat can lower its source level by up to $20 \mathrm{~dB}$ when hanging without paying with detection range compared to when flying. In fact, at $88 \mathrm{~dB}$ SPL, the echolocation source level we mostly recorded on the perch, the detection distance would be ca. $2.1 \mathrm{~m}$, i.e., substantially longer than when emitting $100 \mathrm{~dB}$ SPL in flight. Thus, in addition to reducing energy consumption from flight, perching may create even larger acoustic advantages from reduced noise and more precise directional information for big-eared than for other bats.

In conclusion, our results show that $T$. cirrhosus emits a very narrow sonar beam both when hanging and flying. To understand the functional and ecological significance of different hunting modes it is important to integrate all aspects of hunting behavior, not only energy consumption, but also the critical features 
of echolocation including intensity and directionality. Our study indicates that the high directionality and moderate sound level in phyllostomid bats are adapted to the mode of hunting, i.e., largely motionless prey in dense clutter, and is not governed or affected by additional sensory cues the bats may receive from their quarry (e.g., passive acoustics, olfactory cues, etc.).

\section{ACKNOWLEDGMENTS}

We are grateful to the Smithsonian Tropical Research Institute for permitting and logistical support and to Patricia Jones for her help with the 2012 bats. We thank Søren Ø. Surlykke for help with the figures, and John M. Ratcliffe for help with statistics. Foremost, we would like to acknowledge our late colleague and dear friend, Elisabeth K. V. Kalko, without whose inspiration, friendship, and passion for understanding the world of bats this project, as well as countless others, would not have been possible. All experiments were licensed and approved by the Smithsonian Tropical Research Institute (IACUC 2007-14-06-15-07 and 20100816-1012-16) and by the Autoridad Nacional del Ambiente de Panamá (SE/A-94-11).

\section{REFERENCES}

Audet, D., Krull, D., Marimuthu, G., Sumithran, S., and Singh, J. B. (1991). Foraging behavior of the Indian false vampire bat, Megaderma lyra (Chiroptera: Megadermatidae). Biotropica 23, 63-67. doi: 10.2307/2388689

Barclay, R. M. R., Fenton, M. B., Tuttle, M. D., and Ryan, M. J. (1981). Echolocation calls produced by Trachops cirrhosus (Chiroptera: Phyllostomatidae) while hunting for frogs. Can. J. Zool. 59, 750-753. doi: 10.1139/z81-107

Brinkløv, S., Jakobsen, L., Ratcliffe, J. M., Kalko, E. K. V., and Surlykke, A. (2011). Echolocation call intensity and directionality in flying shorttailed fruit bats, Carollia perspicillata (Phyllostomidae). J. Acoust. Soc. Am. 129, 427-435. doi: 10.1121/1. 3519396

Brinkløv, S., Kalko, E. K. V., and Surlykke, A. (2010). Dynamic adjustment of biosonar intensity to habitat clutter in the bat Macrophyllum macrophyllum (Phyllostomidae). Behav. Ecol. Sociobiol. 64, 1867-1874. doi: 10.1007/s00265-010-0998-9

Brüel, and Kjær (1982). Condenser Microphones and Microphone Preamplifiers for Acoustic Measurements: Data Handbook. Nærum: Brüel and Kiær.

Feng, L., Gao, L., Lu, H., and Müller, R. (2012). Noseleaf dynamics during pulse emission in horseshoe bats. PLoS ONE 7:e34685. doi: 10.1371/journal.pone. 0034685

Fenton, M. B., Cumming, D. H. M., Hutton, J. M., and Swanepoel, C. M. (1987). Foraging and habitat use by Nycteris grandis (Chiroptera: Nycteridae) in Zimbabwe. J. Zool. 211, 709-716. doi: 10.1111/j.14697998.1987.tb04481.x

Goerlitz, H. R., Ter Hofstede, H. M., Zeale, M. R. K., Jones, G., and Holderied, M. W. (2010). An aerial-hawking bat uses stealth echolocation to counter moth hearing. Curr. Biol. 20,
1568-1572. doi: 10.1016/j.cub.2010. 07.046

Hartley, D. J., and Suthers, R. A. (1987). The sound emission pattern and the acoustical role of the noseleaf in the echolocating bat, Carollia perspicillata. J. Acoust. Soc. Am. 82, 1892-1900. doi: 10.1121/1.395684

Hoffmann, S., Baier, L., Borina, F., Schuller, G., Wiegrebe, L., and Firzlaff, U. (2008). Psychophysical and neurophysiological hearing thresholds in the bat Phyllostomus discolor. J. Comp. Physiol. A 194, 39-47. doi: 10.1007/s00359-007-0288-9

Jakobsen, L., Kalko, E., and Surlykke, A. (2012). Echolocation beam shape in emballonurid bats, Saccopteryx bilineata and Cormura brevirostris. Behav. Ecol. Sociobiol. 66, 1493-1502. doi: 10.1007/s00265-012-1404-6

Jakobsen, L., Ratcliffe, J. M., and Surlykke, A. (2013). Convergent acoustic field of view in echolocating bats. Nature 493, 93-96. doi: 10.1038/nature11664

Jakobsen, L., and Surlykke, A. (2010). Vespertilionid bats control the width of their biosonar sound beam dynamically during prey pursuit. Proc. Natl. Acad. Sci. U.S.A. 107, 13930-13935. doi: 10.1073/pnas.1006630107

Jones, G., and Rayner, J. M. V. (1989). Foraging behavior and echolocation of wild horseshoe bats Rhinolophus ferrumequinum and R. hipposideros (Chiroptera, Rhinolophidae). Behav. Ecol. Sociobiol. 25, 183-191. doi: 10.1007/BF00302917

Kalko, E. K. V., Friemel, D., Handley, C. O. J., and Schnitzler, H. U. (1999). Roosting and foraging behavior of two Neotropical gleaning bats, Tonatia silvicola and Trachops cirrhosus (Phyllostomidae). Biotropica 31, 344-353. doi: 10.1111/j.17447429.1999.tb00146.x

LaVal, R. K., and Rodrìguez-H, B. (2002). Murcieilagos de Costa Rica BATS. Santo Domingo, Heredia: Editorial INBio.
Long, G. R. (1977). Masked auditory thresholds from the bat, Rhinolophus ferrumequinum. J. Comp. Physiol. A 116, 247-255. doi: 10.1007/BF00605406

Møhl, B., Wahlberg, M., Madsen, P. T., Heerfordt, A., and Lund, A. (2003). The monopulsed nature of sperm whale clicks. J. Acoust. Soc. Am. 114, 1143-1154. doi: 10.1121/ 1.1586258

Moss, C. F., Chiu, C., and Surlykke, A. (2011). Adaptive vocal behavior drives perception by echolocation in bats. Curr. Opin. Neurobiol. 21, 645-652. doi: 10.1016/j.conb.2011. 05.028

Neuweiler, G. (1989). Foraging ecology and audition in echolocating bats. Trends Ecol. Evol. 4, 160-166. doi: 10.1016/0169-5347 (89)90120-1

Neuweiler, G., Metzner, W., Heilman, U., Rübsamen, R., Eckrich, M., and Costa, H. H. (1987). Foraging behaviour and echolocation in the rufous horseshoe bat (Rhinolophus rouxi) of Sri Lanka. Behav. Ecol. Sociobiol. 20, 53-67. doi: 10.1007/BF00292166

Page, R. A., and Ryan, M. J. (2008). The effect of signal complexity on localization performance in bats that localize frog calls. Anim. Behav. 76, 761-769. doi: 10.1016/j.anbehav.2008.05.006

Page, R. A., Schnelle, T., Kalko, E. K. V., Bunge, T., and Bernal, X. E. (2012). Sequential assessment of prey through the use of multiple sensory cues by an eavesdropping bat. Naturwissenschaften 99, 505-509. doi: 10.1007/s00114-0120920-6

Reid, F. (1997). A Field Guide to the Mammals of Central America and Southeast Mexico. New York, NY: Oxford University Press.

Ryan, M. J., Tuttle, M. D., and Barclay, R. M. R. (1983). Behavioral responses of the frog-eating bat, Trachops cirrhosus, to sonic frequencies. J. Comp.
Physiol. A 150, 413-418. doi: 10.1007/BF00609567

Ryan, M. J., Tuttle, M. D., and Rand, A. S. (1982). Bat predation and sexual advertisement in a neotropical anuran. Am. Nat. 119, 136-139. doi: $10.1086 / 283899$

Schnitzler, H.-U. (1967). Kompensation von Dopplereffekten bei Hufeisen-Fledermäusen. Naturwissenschaften 54, 523-523. doi: 10.1007/BF01129387

Schnitzler, H.-U., and Kalko, E. K. V. (2001). Echolocation by insecteating bats. Bioscience 51, 557-569. doi: $\quad 10.1641 / 0006-3568(2001)$ 051[0557:EBIEB]2.0.CO;2

Speakman, J. R., and Racey, P. (1991). No cost of echolocation for bats in flight. Nature 350, 421-423. doi: 10.1038/350421a0

Surlykke, A., Filskov, M., Fullard, J. H., and Forrest, E. (1999). Auditory relationships to size in noctuid moths: bigger is better. Naturwissenschaften 86, 238-241. doi: 10.1007/s001 140050607

Surlykke, A., and Kalko, E. K. V. (2008). Echolocating bats cry out loud to detect their prey. PLoS ONE 3:e2036. doi: 10.1371/journal.pone. 0002036

Surlykke, A., Ghose, K., and Moss, C. F. (2009a). Acoustic scanning of natural scenes by echolocation in the big brown bat, Eptesicus fuscus. J. Exp. Biol. 212, 1011-1020. doi: 10.1242/jeb.024620

Surlykke, A., Pedersen, S. B., and Jakobsen, L. (2009b). Echolocating bats emit a highly directional sonar sound beam in the field. Proc. Biol. Sci. 276, 853-860. doi 10.1098/rspb.2008.1505

Tuttle, M. D., and Ryan, M. J. (1981). Bat predation and the evolution of frog vocalization in the neotropics. Science 214, 677-678. doi: 10.1126/science. 214.4521.677

Vanderelst, D., De Mey, F., Peremans, H., Geipel, I., Kalko, E. K. V., and Firzlaff, U. (2010). What 
noseleaves do for FM bats depends on their degree of sensorial specialization. PLOS ONE 5:e11893. doi: 10.1371/journal. pone.0011893

Voigt, C., Schuller, B. M., Greif, S., and Siemers, B. (2010). Perch-hunting in insectivorous Rhinolophus bats is related to the high energy costs of manoeuvring in flight. J. Comp. Physiol. B 180, 1079-1088. doi: 10.1007/s00360010-0466-x

Weinbeer, M., and Kalko, E. K. V. (2004). Morphological characteristics predict alternate foraging strategy and microhabitat selection in the orange-bellied bat, Lampronycteris brachyotis. J. Mamm. 85, 1116-1123. doi: 10.1644/BWG-206.1

Weinbeer, M., and Kalko, E. K. V. (2007). Ecological niche and phylogeny: the highly complex echolocation behavior of the trawling long-legged bat, Macrophyllum macrophyllum. Behav. Ecol. Sociobiol. 61, 1337-1348. doi: 10.1007/s00265007-0364-8
Conflict of Interest Statement: The authors declare that the research was conducted in the absence of any commercial or financial relationships that could be construed as a potential conflict of interest.

Received: 06 March 2013; accepted: 26 May 2013; published online: 28 June 2013

Citation: Surlykke A, Jakobsen L, Kalko EKV and Page RA (2013) Echolocation intensity and directionality of perching and flying fringe-lipped bats, Trachops cirrhosus (Phyllostomidae). Front.
Physiol. 4:143. doi: 10.3389/fphys 2013.00143

This article was submitted to Frontiers in Integrative Physiology, a specialty of Frontiers in Physiology.

Copyright (C) 2013 Surlykke, Jakobsen, Kalko and Page. This is an openaccess article distributed under the terms of the Creative Commons Attribution License, which permits use, distribution and reproduction in other forums, provided the original authors and source are credited and subject to any copyright notices concerning any third-party graphics etc. 